\title{
Multi-responsive shape memory polymer printed by fused deposition modeling technique
}

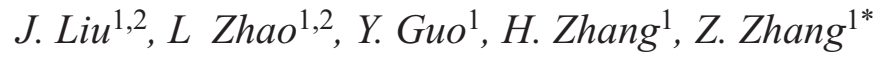 \\ ${ }^{1}$ CAS Key Laboratory of Nanosystem and Hierarchical Fabrication, CAS Center for Excellence in Nanoscience, National \\ Center for Nanoscience and Technology, 100190 Beijing, China \\ ${ }^{2}$ University of Chinese Academy of Sciences, 100049 Beijing, China
}

Received 2 September 2019; accepted in revised form 5 November 2019

\begin{abstract}
With the help of three-dimensional (3D) printing technique, complicated and sophisticated structured shape memory polymers (SMPs) devices could be obtained, which have drawn tremendous attention in recent years. However, there is technical limitation for 3D photo-polymerization printing technique to prepare multi-responsive SMP devices. A major problem for this is that functional fillers added to the photo-curing resins disturb or even inhibit their photo polymerization process. Herein, we demonstrated that the fused deposition modeling (FDM) technology seems more promising for fabrication of multi-responsive SMP devices. In this research, SMP devices are printed using a new material, polycyclooctene (PCO), whose application in FDM printing is never reported in the previous work. A universal and facile method, gammaray irradiation, is used to realize the crosslinking of printed structures. The printing quality and thermo-responsive speed of SMPs can be improved by incorporation of highly thermal conductive fillers (hexagonal boron nitride, BN) to PCO; in addition, after the addition of multiwalled carbon nanotubes (MWCNTs), the 3D SMP devices obtained multi-responsive ability owing to the enhanced electrical conduction and light absorption of the composite materials.
\end{abstract}

Keywords: polymer composites, fused deposition modeling (FDM), shape memory polymers (SMPs), multi-responsive

\section{Introduction}

Three-dimensional (3D) printing has drawn tremendous attention from both academia and industry with its potential applications in various fields, such as electronic [1], soft robots [2], medical [3], and pharmaceutical [4] domains. It has become a common method for manufacturing objects with complex [5, $6]$, unusual geometries $[7,8]$, and special functions $[9,10] .3 \mathrm{D}$ printing shape-morphing systems, which are also called four-dimensional (4D) printing, have attracted much attention recent years [11-14]. The ways to achieve shape-morphing are various, such as bilayer system $[15,16]$, uneven expansion $[17,18]$, shape memory material $[7,19,20]$, and so on.

Among them, shape memory polymers (SMPs) are widely applied in $4 \mathrm{D}$ printing owing to their many advantages. SMPs have enjoyed a long history of interest and academic development due to their broad tunable range of mechanical, thermal, optical properties, low density and low cost, compared to shape memory alloys [21]. They can keep the temporary shape stable for a long time and recover to the permanent shape upon exposure to an external stimulus [22-24] such as light [25], heat [26-29], PH change [30], and electromagnetic field [31, 32]. Currently, most of such devices are fabricated based on thermal-responsive shape memory polymers, which exhibit a mechanical response when triggered only by heat $[7,19,20]$. However, direct heating is often limited in practical applications. Thus, electricity and light as external triggers are attracting notable interest on account of their capability for remote control, 
accurate focusing, and rapid switching of properties $[33,34]$. Adding fillers to matrix, or modifying the polymer chain by functional groups are the most useful methods to achieve electro-response and photoresponse [35-37].

However, addition of fillers to photo-curing resins will decrease their transmittance significantly, which leads to incomplete cure or even failure cure of resin, thus limiting their applications in 3D photo-polymerization printing. Additionally, the photo-responsive groups of functional materials can undergo significant conformation or structure transitions when exposed to UV illumination during 3D printing, which may affect the shape memory property of the composites. Moreover, it is difficult for frequently-used thermosetting polymers, such as methacrylate and epoxy acrylate, to realize recovery under electro- or photo stimuli at lower temperatures because of their relative higher glass transition temperatures $\left(T_{\mathrm{g}}\right)$. Comparatively, fused deposition modeling (FDM) technology attracted our attention, which is suitable for printing thermoplastic polymers. By adding functional fillers, thermoplastic polymers could obtain additional enhanced properties, such as high electrical conductivity, high thermal conductivity, high light absorption, and so on, which are important to achieve multi-response. The relatively lower $T_{\mathrm{g}}$ of thermoplastic polymers are conducive to realize multi-response.

In order to fabricate 3D multi-responsive devices by FDM, polycyclooctene (PCO) is chosen owing to its excellent shape memory property (recoverable strain over $700 \%$ [38]) and suitable melting temperature (ca. $55^{\circ} \mathrm{C}$ ). To date, no paper has succeeded in developing $\mathrm{PCO}$ filaments for $3 \mathrm{D}$ printing applications. A universal and facile method, gamma-ray $(\gamma$-ray) irradiation, is used to realize the crosslinking of printed structures. The irradiated structures show excellent shape memory effect. Hexagonal boron nitride (BN) with excellent thermal conductivity, has been applied as filler to improve the thermo-response speed and the mechanical properties of 3Dprinted PCO structures. Moreover, multiwalled carbon nanotubes (MWCNTs) with excellent electrical conductivity and photo-thermal conversion efficiency are added into PCO endows 3D printable shape memory devices to fabricate multi-responsive devices.

\section{Experimental section}

\subsection{Materials}

Polycyclooctene (PCO, type Vestenamer 8012) pellets from Evonik Industries AG (Germany) had a density of $0.910 \mathrm{~g} \cdot \mathrm{cm}^{-3}$ and a melt flow index of $16 \mathrm{~g}(10 \mathrm{~min})^{-1}$. Hexagonal boron nitride (PN08) was provided by Zibo Jonye Ceramics Technology Co., Ltd., which has an averaged particle size of $8 \mu \mathrm{m}$. MWCNTs with a purity greater than $95 \%$, outer diameter of $20-30 \mathrm{~nm}$, and length of $10-30 \mu \mathrm{m}$ were purchased from Chengdu Organic Chemical Co. Ltd., Chinese Academy of Sciences, China.

\subsection{Preparation of $\mathrm{BN} / \mathrm{PCO}, \mathrm{MWCNTs} / \mathrm{PCO}$ and PCO filament.}

$\mathrm{BN}$ platelets or MWCNTs were fully dispersed in PCO to prepare composites using an internal mixer (HAAKE Industries, Germany) at $70^{\circ} \mathrm{C}, 60 \mathrm{r} / \mathrm{min}$ for $25 \mathrm{~min}$. The composites were cut into the little particles followed by extruding using a single-screw extruder (HAAKE Industries, Germany) to form filament suitable for fused deposition molding 3D printer. With careful control of the extrude temperature and tensile speed, filaments with a circular cross section of average diameter of $1.75 \mathrm{~mm}$ were produced.

\subsection{D printing and irradiation}

Different 3D digital models were designed using SolidWorks 2010 to meet various experiments. Objects were printed using a Cubicon Single 3DP-110F desktop 3D printer (Cubicon Industries, Korea) with standard setting: e.g. $220^{\circ} \mathrm{C}$ nozzle temperature, $30^{\circ} \mathrm{C}$ chamber temperature and $40^{\circ} \mathrm{C}$ printed bed temperature. In the case of pure PCO, nitrogen was blown onto the samples during printing process to increase cooling rate.

All printed objects were crosslinked by $\gamma$-ray irradiation with irradiation dose from 50 to $200 \mathrm{kGy}$.

\subsection{Characterization}

The thermal stability of composites was checked on a TGA (TA Instruments Q500, USA) under a nitrogen atmosphere with the temperature range from a room temperature of ca. 25 to $800^{\circ} \mathrm{C}$ at a heating rate of $10^{\circ} \mathrm{C} \cdot \mathrm{min}^{-1}$.

The mechanical properties of PCO and composites were measured by Dynamic mechanical analysis (DMA, TA Instruments Q800, USA) in the tensile 
mode from -50 to $60^{\circ} \mathrm{C}$ at a heating rate of $10^{\circ} \mathrm{C} \cdot \mathrm{min}^{-1}$. The dimensions of the samples were ca. $2.0 \times 10.0 \times 0.2 \mathrm{~mm}^{3}$. Five samples were tested for each composition, and the most representative curve was plotted.

The thermal conductivity of the composites was measured on a comprehensive physical property measurement system (PPMS-9, American Quantum Design, USA) at $25^{\circ} \mathrm{C}$.

The curing and phase transitions of c-PCO and nanocomposites were measured on a DSC (TA Instruments Q2000, USA) in temperature modulation mode under a nitrogen atmosphere $\left(50 \mathrm{~mL} \cdot \mathrm{min}^{-1}\right)$. The calibration of temperature and enthalpy was performed with indium. 3-7 mg samples were sealed in aluminum crucibles. The scan rate for non-isothermal measurements was $10^{\circ} \mathrm{C} \cdot \mathrm{min}^{-1}$. Three samples were tested for each composition, and the most representative one was plotted.

The electrical conductivity $(\sigma)$ of MWCNTs/c-PCO nanocomposites was calculated by Equation (1):

$\sigma=\frac{1}{\rho}=\frac{L}{R \cdot S}$

where $R$ is the resistance of sample, $S$ is the crosssection of sample, $L$ is the length of sample. The resistance of sample was measured by Keithley DMM7510.

To measure the gel fraction $(f)$, each sample was extracted using boiling THF for $24 \mathrm{~h}$, and then vacuum-dried at $50{ }^{\circ} \mathrm{C}$ to remove residual solvent. Gel fraction values of pure PCO were calculated using the initial dry weight, before extraction, $W_{\mathrm{i}}$, and the dry weight after extraction, $W_{\mathrm{d}}$, by the following Equation (2):

$f=\frac{W_{\mathrm{d}}}{W_{\mathrm{i}}} \cdot 100 \%$

The $f$ of the $\mathrm{BN} / \mathrm{c}-\mathrm{PCO}$ composites was calculated by the following Equation (3):
$f=\frac{W_{\mathrm{d}}-M_{\mathrm{f}} W_{\mathrm{i}}}{\left(1-M_{\mathrm{f}}\right) W_{\mathrm{i}}}$

where $M_{\mathrm{f}}$ is the mass fraction of $\mathrm{BN}$.

The photo-response test was taken by a solar simulator (91159A, Newport Corporation, USA). The illumination intensity is $100 \mathrm{~mW} / \mathrm{cm}^{2}$.

In order to show the electro-responsive property, the voltage was applied on the sample using a DC power source (UTP3315-L, UNI-T Corporation). Copper wires were adhered to samples by conductive silver adhesive as the electrodes.

\section{Results and discussion}

\subsection{Thermal-responsive BN/PCO composites printed by FDM}

Figure 1 schematically shows the fabrication process of the 3D printed SMPs device and their recovery process. First, device is fabricated through layer-bylayer deposition; $\gamma$-ray is then used to irradiate the sample to crosslink and endows the shape memory effect; finally, external force is applied to the irradiated structures to fix temporary shape and recover to the original shape under stimulation.

As mentioned above, PCO is a good choice for FDM 3D printing to fabricate multi-responsive devices, but there are still many challenges in developing high-quality filaments for 3D FDM printing. At relative low printing temperature $\left(110^{\circ} \mathrm{C}\right)$, the viscosity of melt PCO is really high, which makes it difficult to extrude and bend. At high printing temperature $\left(240^{\circ} \mathrm{C}\right)$, the viscosity of PCO decreases, and the melt PCO can be extruded fluently. However, the melt PCO creeps easily at such a high temperature and to keep the designed shape is hard. Here we found that addition of BN can effectively improve the printing quality of PCO probably owing to the enhanced modulus and cooling rate of the melt BN/PCO. A series of BN/PCO composites are prepared with various $\mathrm{BN}$ loading ranging from

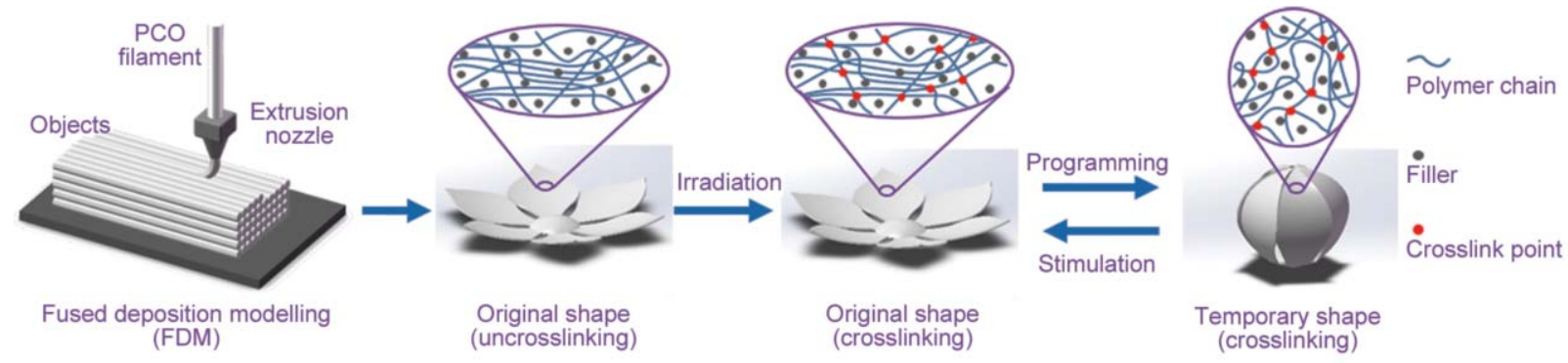

Figure 1. The fabrication process of multi-responsive device printed by FDM 3D printing. 
5 to $20 \mathrm{wt} \%$ using internal mixer, and then, extruded to form filaments with average diameter of $1.75 \mathrm{~mm}$ suitable for the commercial FDM 3D printer (see details in Experimental Section 2.2). The PCO and BN/PCO composite samples are
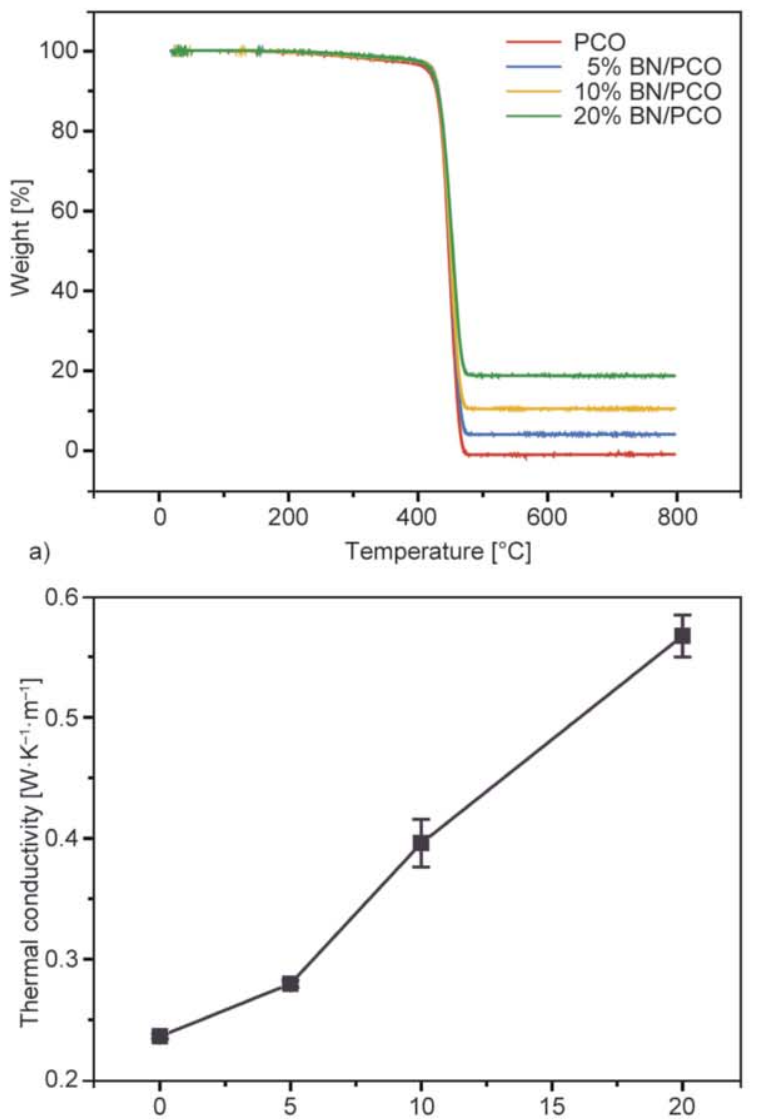

c)
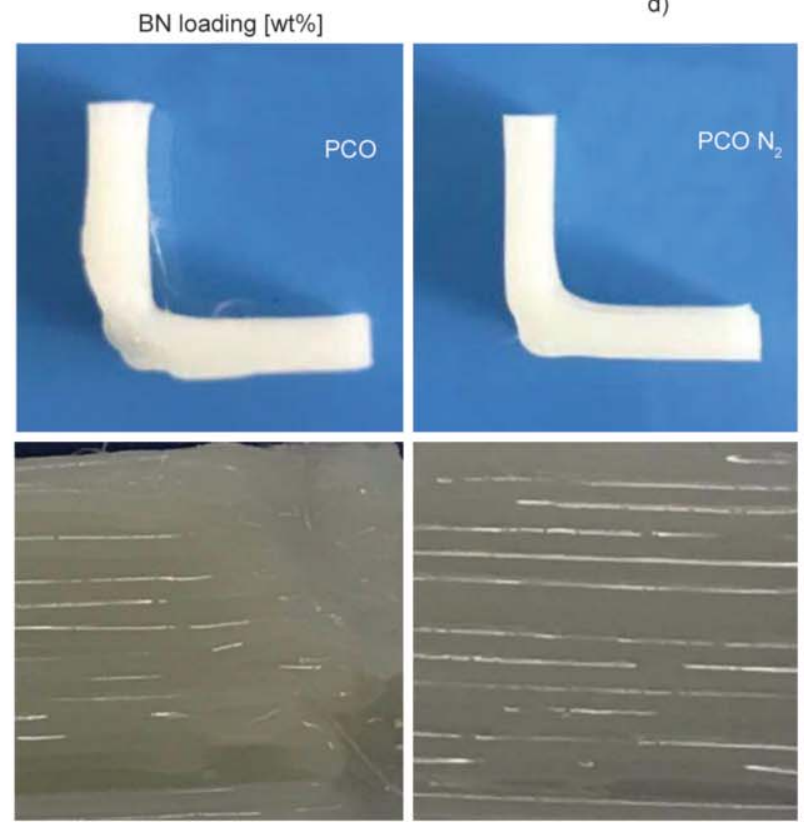

e)
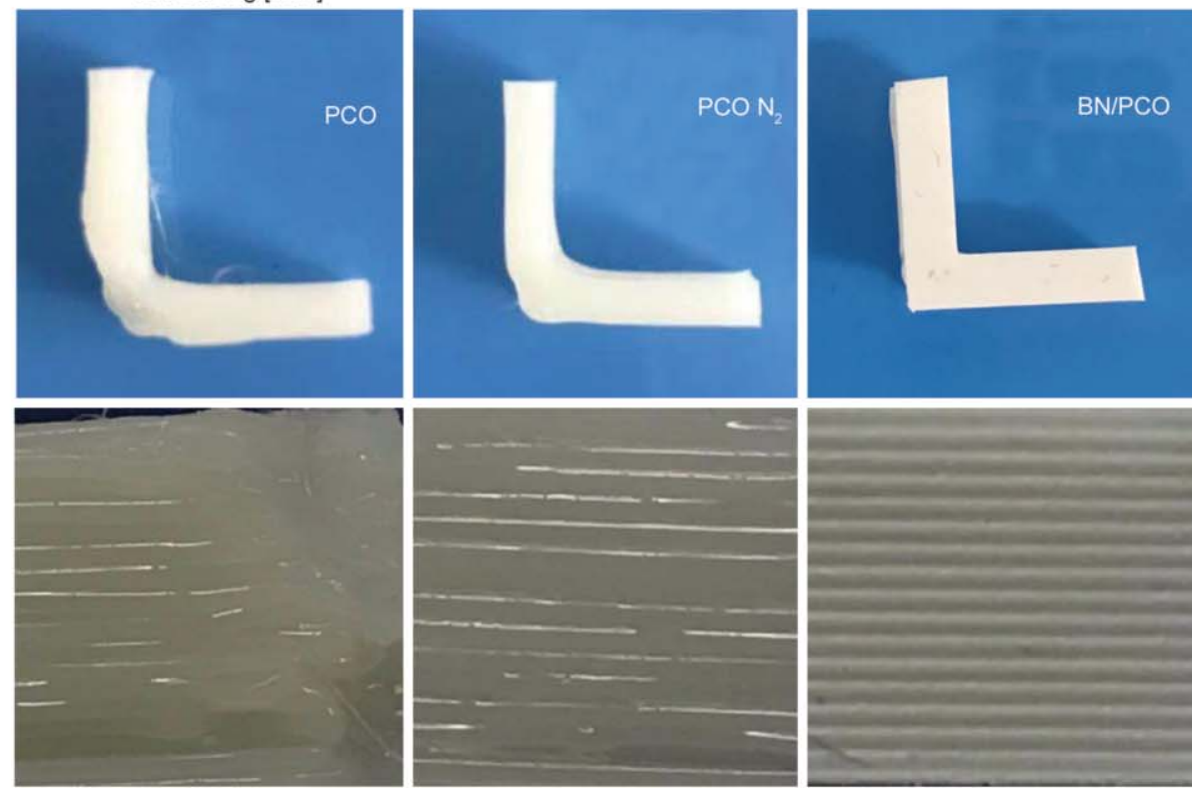

Figure 2. (a) TGA curve of BN/PCO composites with different BN loading. (b) The storage modulus of samples with different $\mathrm{BN}$ loading at -50 and $60^{\circ} \mathrm{C}$. (c) Thermal conductivity of the BN/PCO composites with different BN loading. (d) Filaments of PCO and BN/PCO composites with $20 \mathrm{wt} \%$ filler content. (e) The images of different printed objects, top view (top) and front view (bottom).

crosslinked by $\gamma$-ray irradiation for further test. In order to distinguish the PCO composites before and after irradiation, the crosslinked $\mathrm{PCO}$ and $\mathrm{BN} / \mathrm{PCO}$ composites after irradiation are named as c- $\mathrm{PCO}$ and $\mathrm{BN} / \mathrm{c}-\mathrm{PCO}$.
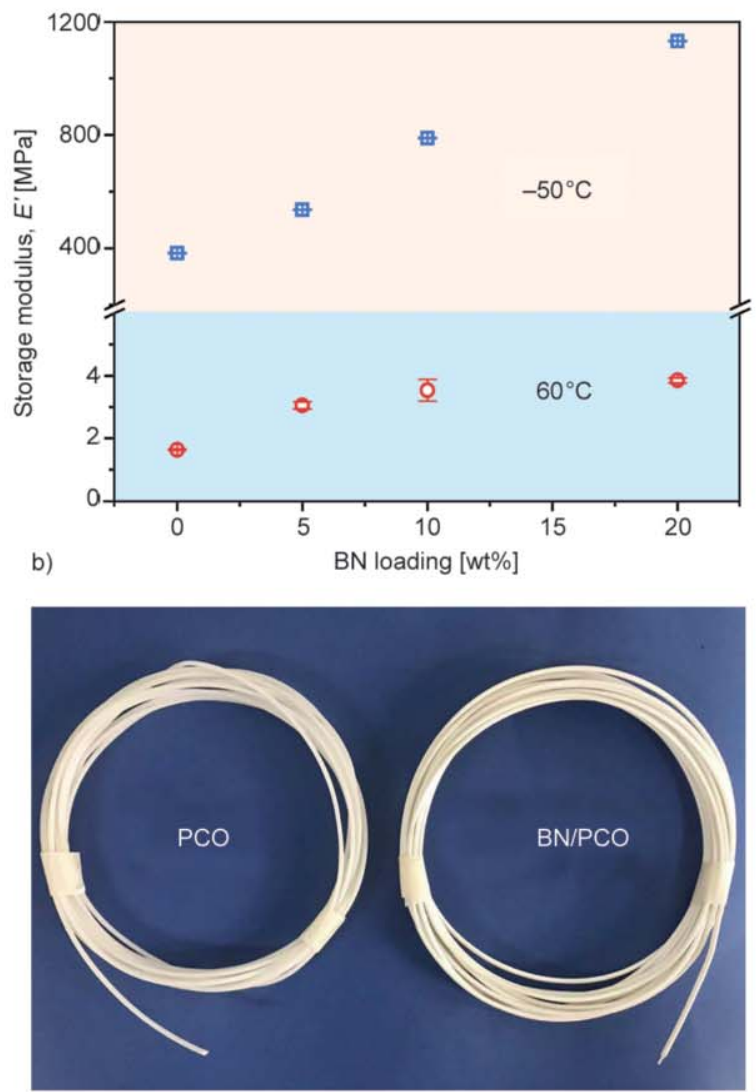

d) 
The thermal behaviors of PCO and BN/PCO composites are shown in Figure 2a. BN/PCO composites show similar thermal decomposition behavior to pure PCO. The thermal stability of composites can be slightly improved with the addition of BN. The reason can be ascribed to the high thermal conductivity and high thermal capacity of the BN, which can absorb a lot of heat and delay the decomposition of the composites $[39,40]$. The onset decomposition temperatures ( $T_{\text {onset }}$, the temperature of $5 \%$ weight lost) of PCO and BN/PCO composites are over $400^{\circ} \mathrm{C}$. Therefore, the printing process $\left(220^{\circ} \mathrm{C}\right)$ does not cause the decomposition of materials. To investigate the mechanical properties of the $\mathrm{BN} / \mathrm{PCO}$ composites, tensile tests are conducted at -50 and $60^{\circ} \mathrm{C}$, and the results are shown in Figure $2 b$. With the addition of $\mathrm{BN}$ microplates, the storage modulus $\left(E^{\prime}\right)$ increases significantly from 383 to $1132 \mathrm{MPa}$ at $-50^{\circ} \mathrm{C}$ and from 1.63 to $3.85 \mathrm{MPa}$ at $60^{\circ} \mathrm{C}$. The enhanced modulus of BN/PCO composites could effectively prevent the bending of filament during printing. On the other hand, the thermal conductivity $\left(k_{\mathrm{T}}\right)$ of the com-

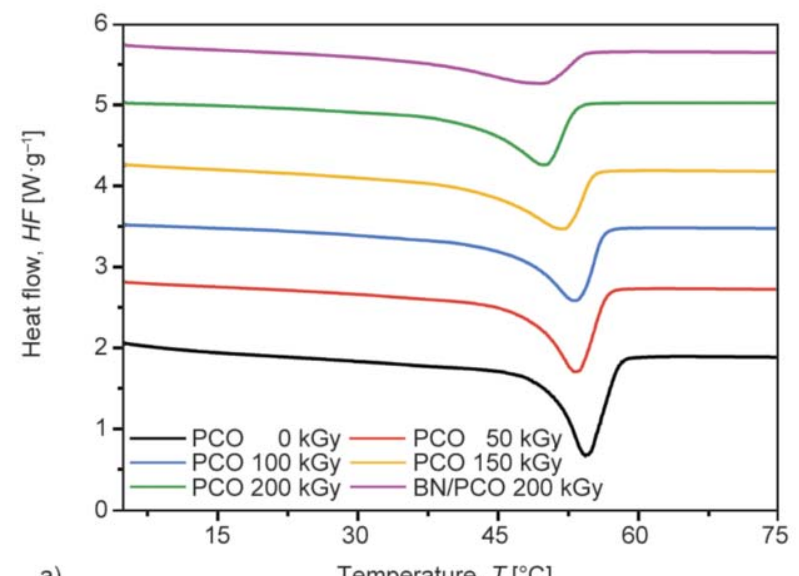

a)

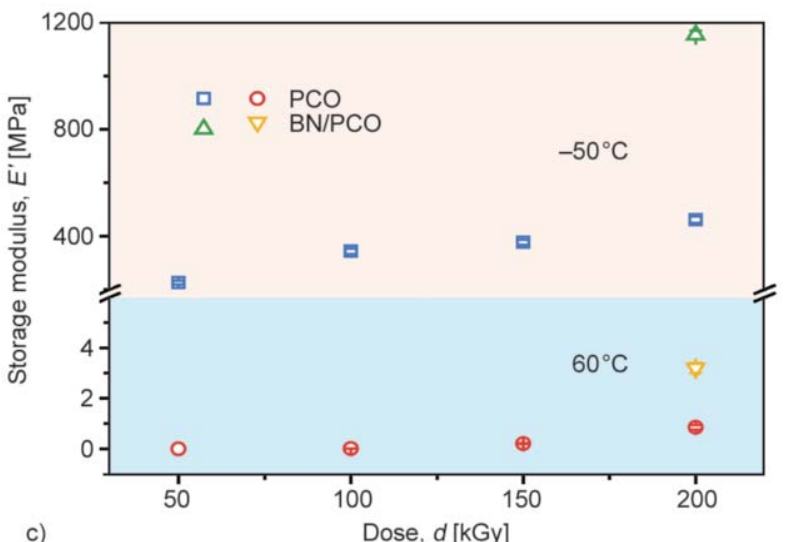

posites is measured and shown in Figure 2c. As expected, $k_{\mathrm{T}}$ of the BN/PCO composites with $20 \mathrm{wt} \%$ BN loading reaches to $0.55 \mathrm{~W} \cdot \mathrm{m}^{-1} \cdot \mathrm{K}^{-1}$, compared to $0.2 \mathrm{~W} \cdot \mathrm{m}^{-1} \cdot \mathrm{K}^{-1}$ of the pure PCO. The high $k_{\mathrm{T}}$ could largely improve the cooling rate of the composites, which is beneficial to enhance the printing quality. Considering the above measurement results, $\mathrm{BN} / \mathrm{PCO}$ composites with $20 \mathrm{wt} \% \mathrm{BN}$ loading is chosen to prepare the $3 \mathrm{D}$ printing shape memory devices. The filaments of PCO and BN/PCO with ca. $1.75 \mathrm{~mm}$ diameter are prepared by twin-screw extruder. The image of filaments is shown in Figure 2d. And the images of printed objects are shown in Figure 2e. As mentioned, due to its low modulus and $k_{\mathrm{T}}$, the printing quality of pure $\mathrm{PCO}$ is poor. Numerous defects can be observed from the image. Nitrogen blowing is used to increase the cooling rate to improve printing quality, which reduces the defects effectively. Among these printed subjects, due to its high $k_{\mathrm{T}}$, $\mathrm{BN} / \mathrm{PCO}$ sample exhibits the best printing quality without any assistant cooling method, as we expected.
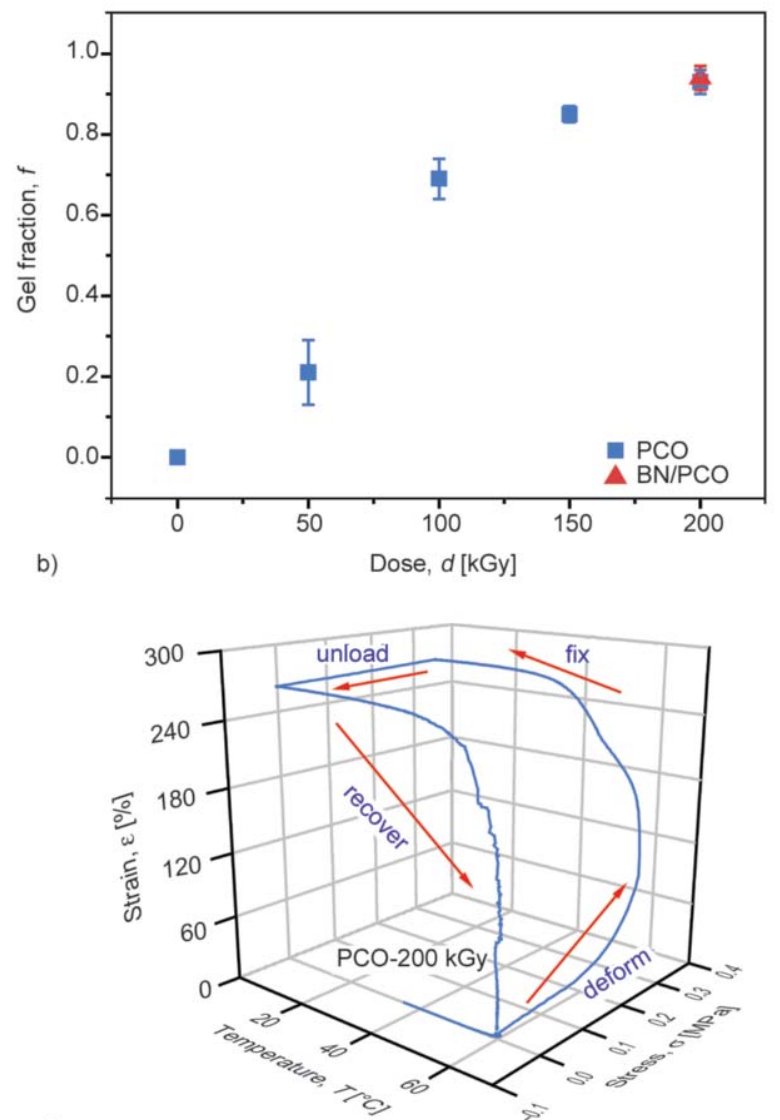

d)

Figure 3. (a) DSC thermographs of PCO-based composite samples with/without irradiation. (b) The gel fraction of c-PCO and BN/c-PCO composites with different dose. (c) The storage modulus of c-PCO and BN/c-PCO samples at -50 and $60^{\circ} \mathrm{C}$ (above $T_{\mathrm{m}}$ ). (d) 3D diagram of shape memory cycles of c-PCO with irradiation of $200 \mathrm{kGy}$. 
The $\mathrm{PCO}$ and $\mathrm{BN} / \mathrm{PCO}$ composites printed by the 3D FDM printer are irradiated by $\gamma$-ray to crosslink. Figure $3 \mathrm{a}$ shows the different scanning calorimetry (DSC) thermographs of heat flow $(H F)$ during heating with different $\gamma$-ray doses for c-PCO and BN/ c-PCO composites at $200 \mathrm{kGy}$. The $T_{\mathrm{m}}$ of pure c-PCO decreases with increasing of irradiation dose. This means at higher crosslink density PCO crystals become imperfect and have lower $T_{\mathrm{m}}$.

To investigate the crosslinking quality, network gel fraction values of the crosslinked samples are measured. Figure $3 \mathrm{~b}$ plots the change of gel fraction for c-PCO and BN/c-PCO composite containing $20 \mathrm{wt} \%$ $\mathrm{BN}$ as a function of irradiation dose. The gel fraction of un-irradiated PCO is zero, indicating no gelation occurs at all. After $\gamma$-ray irradiation, the gel fraction of c-PCO increases up to $69 \%$ at $100 \mathrm{kGy}$ and to $92 \%$ at $200 \mathrm{kGy}$. The gel fraction of BN/c-PCO composites also reaches $94 \%$ at $200 \mathrm{kGy}$, which indicates that the three-dimensional network structure of c-PCO molecules can be formed by the $\gamma$-ray irradiation at $200 \mathrm{kGy}$.

Tensile tests are also conducted at -50 and $60^{\circ} \mathrm{C}$ to investigate the mechanical properties of the composites under different irradiation doses (Figure 3c). As shown in Figure 3c, the storage modulus of the c-PCO and BN/c-PCO composite are improved with increasing of irradiation doses. The storage modulus also exhibits a dramatic increase with the addition of BN of ca. $300 \%$ both in -50 and $60^{\circ} \mathrm{C}$.

$3 \mathrm{D}$ diagram of shape memory cycles of c-PCO after irradiation of $200 \mathrm{kGy}$ is shown in Figure 3d. High shape fixity and recovery can be seen from the figure. The strain fixity ratio $\left(R_{\mathrm{f}}\right)$ and the strain recovery

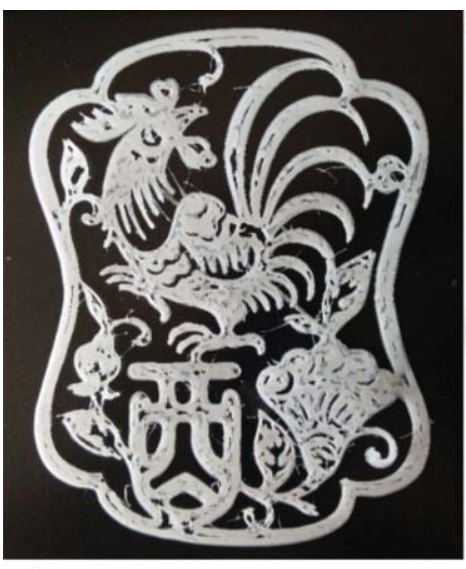

a) ratio $\left(R_{\mathrm{r}}\right)$ for the samples are calculated as following Equations (4) and (5):

$R_{\mathrm{f}}=\frac{\varepsilon_{\text {fix }}}{\varepsilon_{\text {load }}} \cdot 100 \%$

$R_{\mathrm{r}}=\frac{\varepsilon_{\mathrm{fix}}-\varepsilon_{\mathrm{rec}}}{\varepsilon_{\mathrm{fix}}} \cdot 100 \%$

where $\varepsilon_{\text {load }}, \varepsilon_{\text {fix }}$, and $\varepsilon_{\text {rec }}$ are the maximum strain under load, the fixed strain after cooling and load removal, and the strain after recovery, respectively. $R_{\mathrm{f}}$ and $R_{\mathrm{r}}$ for c-PCO and $\mathrm{BN} / \mathrm{c}-\mathrm{PCO}$ composites are summarized in Table 1. With the increase of irradiation dose, both $R_{\mathrm{f}}$ and $R_{\mathrm{r}}$ increase due to the increased crosslinking degree. The high $R_{\mathrm{f}}$ and $R_{\mathrm{r}}$ of c-PCO and BN/c-PCO composite under 200 kGy irradiation indicate their excellent shape effect.

To demonstrate the printability of well-prepared filaments, various objects are printed by FDM 3D printer and are shown in Figure 4. A rooster grille, representing the Year of the Rooster in China of 2017, is printed using pure PCO (see details in Experimental Section 2.3), as shown in the left of Figure 4a. As mentioned above, pure PCO is hard to cool to $T_{\mathrm{m}}$ quickly to keep shape. So, nitrogen is blown on the samples during printing pure PCO to increase the cooling rate. The thickness of the grille is $0.4 \mathrm{~mm}$. After heating, adding external force, and then cooling

Table 1. The strain fixity ratio $\left(R_{\mathrm{f}}\right)$ and strain recovery ratio $\left(R_{\mathrm{r}}\right)$ of different samples.

\begin{tabular}{|c|c|c|c|c|c|}
\hline & $\begin{array}{l}\text { c-PCO- } \\
50 \mathrm{kGy}\end{array}$ & $\begin{array}{l}\text { c-PCO- } \\
100 \text { kGy }\end{array}$ & \begin{tabular}{|c|} 
c-PCO- \\
150 kGy
\end{tabular} & $\begin{array}{l}\text { c-PCO- } \\
200 \mathrm{kGy}\end{array}$ & $\begin{array}{c}\text { BN/c-PCO- } \\
200 \text { kGy }\end{array}$ \\
\hline & 6.09 & 9 & 97.0 & 98. & 9 \\
\hline$R_{\mathrm{r}} \quad[\%]$ & 90.82 & 87.96 & 93.50 & 98.6 & 99.2 \\
\hline
\end{tabular}

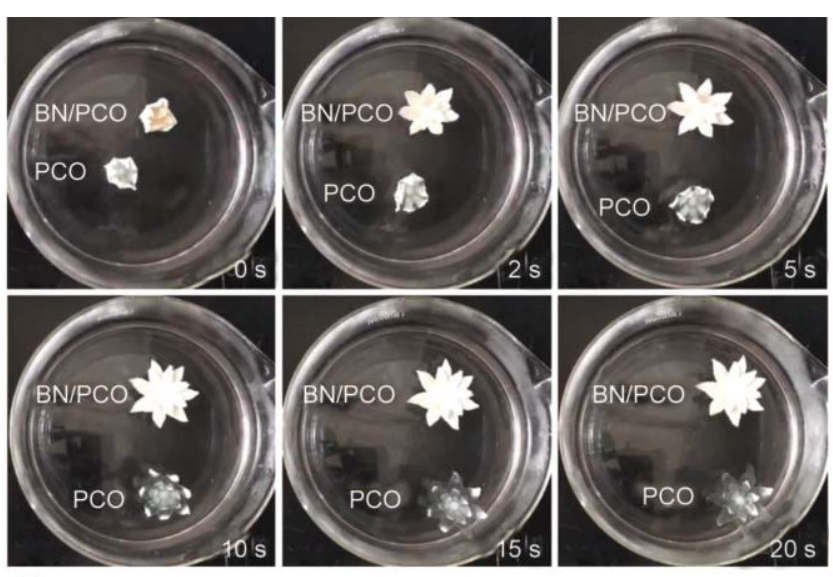

b)

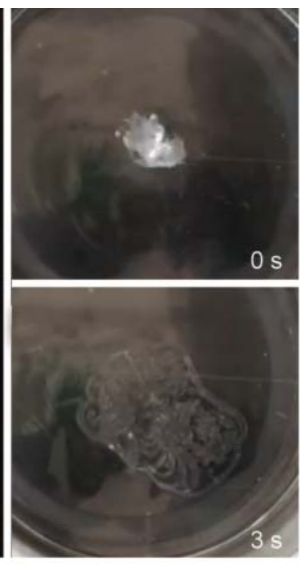

Figure 4. (a) FDM 3D printed rooster grille and its shape recovering process in hot water $\left(\mathrm{ca} .70^{\circ} \mathrm{C}\right)$. The images on the right are obtained in 0 and $3 \mathrm{~s}$, respectively. (b) Comparison of recovering process of c-PCO and BN/c-PCO flowers printed by FDM 3D printer. The images are obtained in $0,2,5,10,15 \mathrm{~s}$, and $20 \mathrm{~s}$, respectively. 
to room temperature, the temporary shape of the grille is fixed from original state. The grille can fully recover from a ball to the original shape when put in the hot water $\left(\mathrm{ca} .70^{\circ} \mathrm{C}\right.$ ), as shown in the right of Figure 4a. To investigate the influence of the addition of $\mathrm{BN}$ on response rate, flowers using c-PCO and $\mathrm{BN} / \mathrm{c}-\mathrm{PCO}$ composite with $\mathrm{BN}$ loading of $20 \%$ are printed and the recovering process are shown in Figure $4 \mathrm{~b}$. It can be clearly seen that the flower with BN fillers shows a much faster response rate compared with the c-PCO flower, due to the enhanced thermal conductivity of the BN/c-PCO composite. The composite sample can recover in $10 \mathrm{~s}$, while the c-PCO sample needs over $20 \mathrm{~s}$ to recover.

\subsection{Multi-responsive device printed by FDM technology}

\subsubsection{Electro-responsive shape memory effect}

Due to their high conductivity, MWCNTs are chosen as the conductive filler to prepare c-PCO composites.
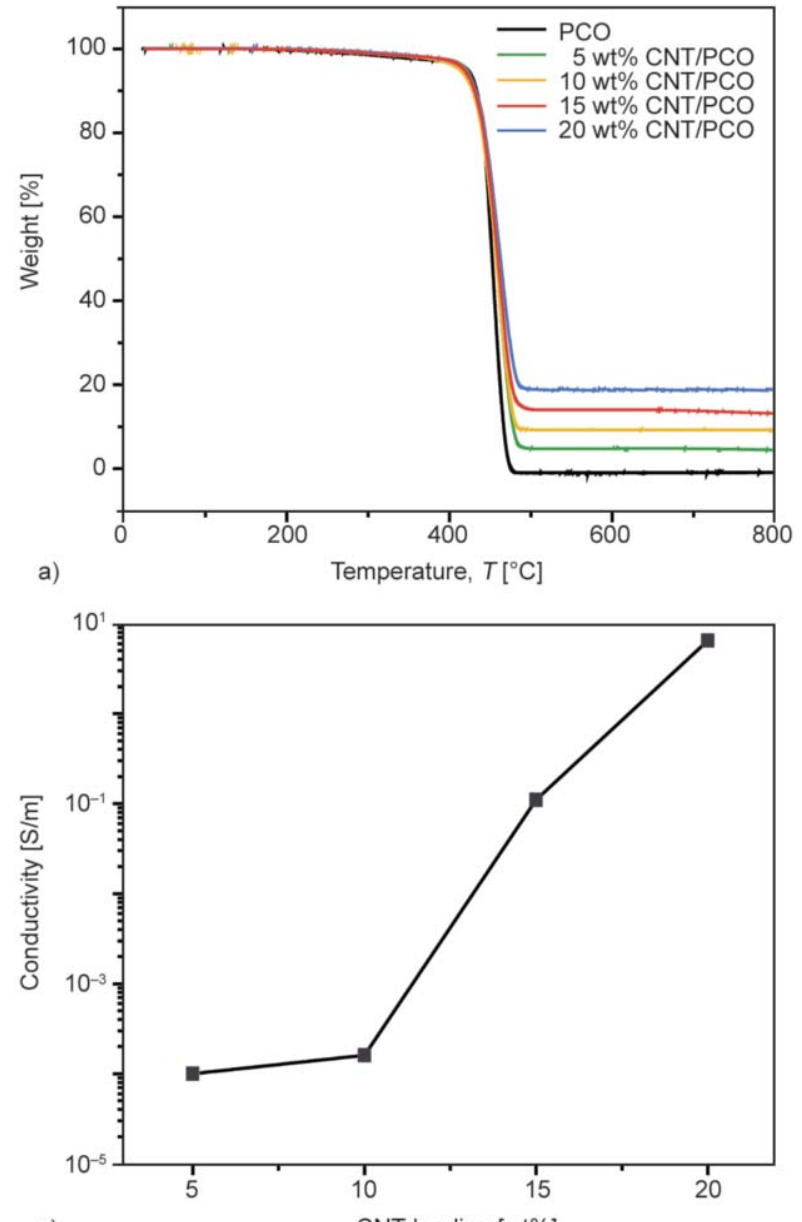

c)

CNT loading [wt \%]
The thermal decomposition behavior of $\mathrm{PCO}$ and MWCNTs/PCO nanocomposites are shown in Figure 5a. A series of MWCNTs/PCO nanocomposites with MWCNTs content ranging from 5 to $20 \mathrm{wt} \%$ are prepared, and extruded to form filaments suitable for 3D FDM printing. (See details in Experimental Section 2.2) As mention above, high mechanical properties are required to ensure the success of printing. Thus, DMA tensile tests of MWCNTs/PCO composites are also conducted at -50 and $60^{\circ} \mathrm{C}$, and the results are shown in Figure $5 \mathrm{~b}$. With the increase of filler loading, the storage modulus shows a remarkable increase both in -50 and $60^{\circ} \mathrm{C}$. When the MWCNTs content comes to $20 \mathrm{wt} \%$, the storage modulus increases significantly from 383 to $1454 \mathrm{MPa}$ at $-50^{\circ} \mathrm{C}$ and from 1.63 to $18.7 \mathrm{MPa}$ at $60^{\circ} \mathrm{C}$. The conductivity of MWCNTs/c-PCO composites is shown in Figure $5 \mathrm{c}$. The electrical conductivity of MWCNTs/ c-PCO composites increases markedly with increasing MWCNTs contents and reaches as high as $6.5 \mathrm{~S} / \mathrm{m}$
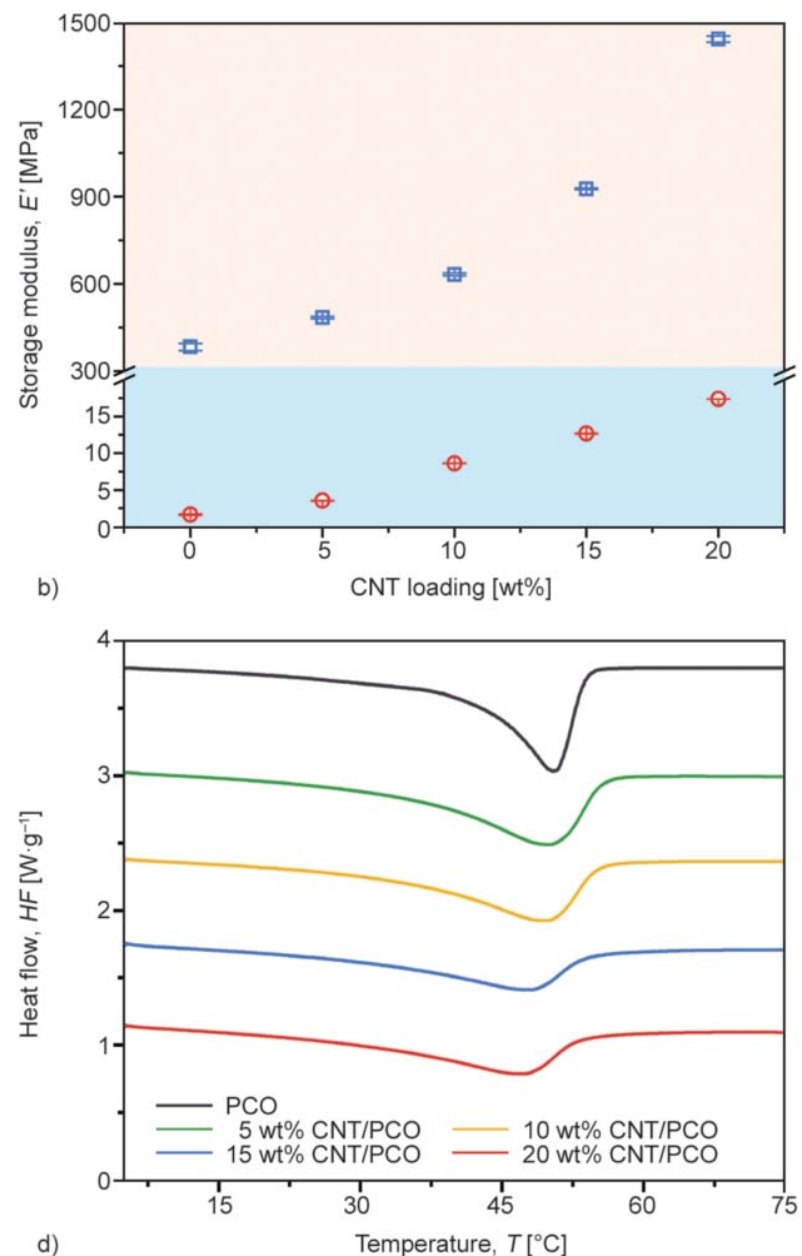

Figure 5. (a) TGA curves of MWCNTs/PCO composites with different MWCNTs loading. (b) The storage modulus of different MWCNTs/PCO samples at -50 and $60^{\circ} \mathrm{C}$. (c) Conductivity of the MWCNTs/c-PCO composites with different MWCNTs loading. (d) DSC curves of MWCNTs/c-PCO composites with different MWCNTs loading. 


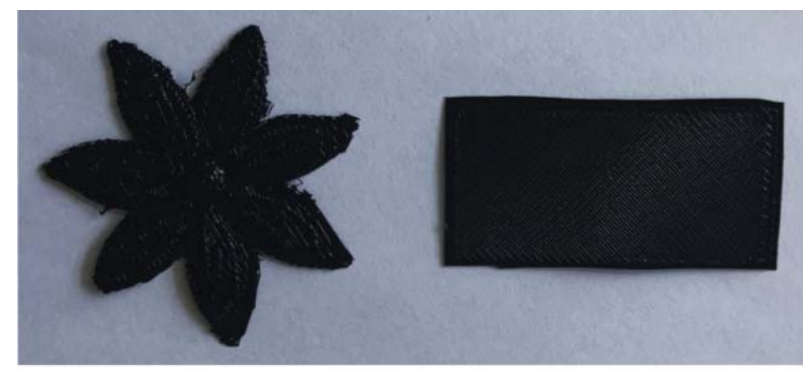

a)

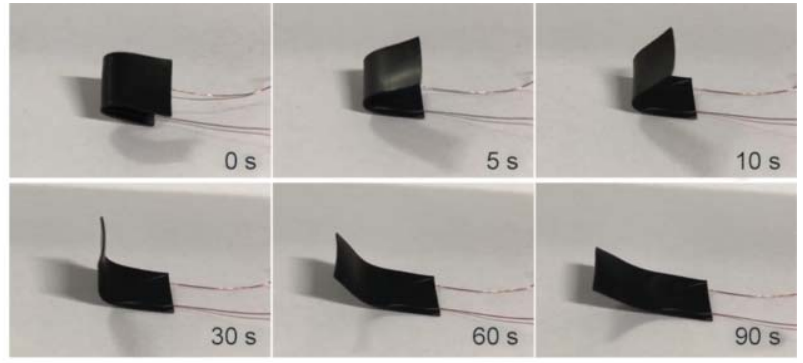

b)

Figure 6. (a) The printed composite samples with $20 \mathrm{wt} \%$ MWCNTs loading and (b) its recovering process. The images of recovering process are obtained in $0,5,10,30,60$, and $90 \mathrm{~s}$, respectively.

at $20 \mathrm{wt} \%$. The appropriate conductivity makes it possible to achieve electro-response under a low voltage. Figure $5 \mathrm{~d}$ shows the DSC thermographs of heat flow during heating of MWCNTs/c-PCO nanocomposites with different filler loadings from 0 to $20 \mathrm{wt} \%$. With the addition of MWCNTs, the $T_{\mathrm{m}}$ of the composites decrease from ca. $51{ }^{\circ} \mathrm{C}$ to ca. $47^{\circ} \mathrm{C}$ due to the inhibiting effect of fillers on polymer crystallization.

The printed structure with $20 \mathrm{wt} \%$ MWCNTs loading and its electro-response recovering process are shown in Figure 6. Beneficial from the high conductivity and relative low $T_{\mathrm{m}}$ of MWCNTs/c-PCO nanocomposite, the sample could recover under a very low voltage, ca. $5 \mathrm{~V}$, which is much lower than that of thermosetting material in literature $(50 \mathrm{~V}){ }^{1}$

\subsubsection{Photo-responsive shape memory effect}

In addition of high conductivity, MWCNTs also exhibits excellent photo-thermal conversion efficiency. Thus, the addition of MWCNTs into PCO endows

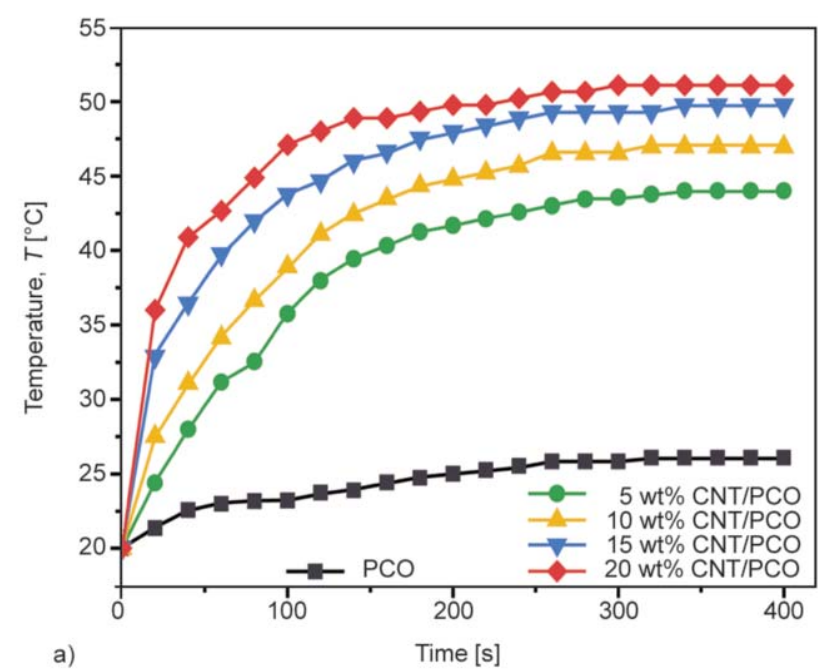

3D printable shape memory devices with photo response.

A series of MWCNTs/PCO films are 3D-printed, irradiated to study the photo-response behavior and the photo-thermal conversion during illumination. The result is shown in Figure 7a. When the loading of MWCNTs in c-PCO increases from 0 to $20 \mathrm{wt} \%$, the maximum temperature after illumination increases from 25.9 to $51.1^{\circ} \mathrm{C}$, indicating the addition of MWCNTs increases the maximum temperature of the composites reached under the same conditions.

According to the above study, a flower is $3 \mathrm{D}$ printed using MWCNTs/c-PCO composite with $20 \mathrm{wt} \%$ filler loading, and then, irradiated by $\gamma$-ray to complete crosslinking. The photo-response recovery process of the flower under illumination is shown in Figure $7 \mathrm{~b}$. As the illumination time increases, the shape of flower petal eventually recovers to its original state, resulting in a shape change from closed to open state. After $200 \mathrm{~s}$ of illumination, full blooming of the flower is achieved.

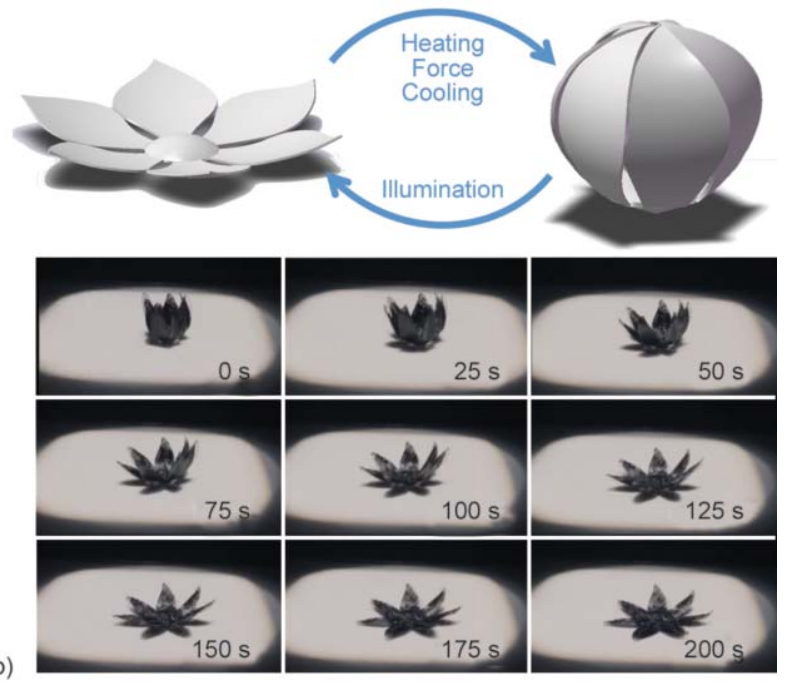

Figure 7. (a) Photo-thermal conversion of shape memory materials with different weight ratios of MWCNTs to c-PCO under a light intensity of $100 \mathrm{~mW} \cdot \mathrm{cm}^{-2}$. (b) The recovery process of printed flower using $20 \mathrm{wt} \% \mathrm{MWCNTs} / \mathrm{c}-\mathrm{PCO}$ composite under a light intensity of $100 \mathrm{~mW} \cdot \mathrm{cm}^{-2}$. The images are obtained every $25 \mathrm{~s}$. 


\section{Conclusions}

In this work, FDM is applied to prepare multi-responsive shape memory PCO and PCO composites filled with functional fillers. The FDM technique can avoid the technical limitation that fillers inhibit photo-polymerization process which often occurs to photo-polymerization printing technique. The addition of $\mathrm{BN}$ to PCO improves the printing quality due to increased modulus and thermal conductivity. The printed devices made of $\mathrm{BN} / \mathrm{c}-\mathrm{PCO}$ composites show better shape memory effect and higher recovery rate compared with pure c-PCO. The addition of MWCNTs endows PCO higher conductivity and relatively lower $T_{\mathrm{m}}$, making it possible to achieve electro-response under very low voltage (ca. $5 \mathrm{~V}$ ), which is difficult to realize for thermosetting materials (like epoxy). The MWCNTs/c-PCO device can recover under light also owing to the excellent photo-thermal conversion efficiency of MWCNTs. The strategy reported here is facile for designing and fabricating multi-responsive shape memory polymer devices, which have great potential applications in the field of customized devices and soft robotics.

\section{Acknowledgements}

This work was financially supported by the National Natural Science Foundation of China (Grant Nos. 11890682, 11832010 and 51861165103), and the National Key Basic Research Program of China (Grant No. 2018YFA0208403).

\section{References}

[1] Valentine A. D., Busbee T. A., Boley J. W., Raney J. R., Chortos A., Kotikian A., Berrigan J. D., Durstock M. F., Lewis J. A.: Hybrid 3D printing of soft electronics. Advanced Materials, 29, 1703817/1-1703817/8 (2017). https://doi.org/10.1002/adma.201703817

[2] Rus D., Tolley M. T.: Design, fabrication and control of soft robots. Nature, 521, 467-475 (2015).

https://doi.org/10.1038/nature14543

[3] Chae M. P., Hunter-Smith D. J., De-Silva I., Tham S., Spychal R. T., Rozen W. M.: Four-dimensional (4D) printing: A new evolution in computed tomographyguided stereolithographic modeling. Principles and application. Journal of Reconstructive Microsurgery, 31, 458-463 (2015).

https://doi.org/10.1055/s-0035-1549006

[4] Zhu W., Li J., Leong Y. J., Rozen I., Qu X., Dong R., Wu Z., Gao W., Chung P. H., Wang J., Chen S.: 3D-Printed artificial microfish. Advanced Materials, 27, 44114417 (2015).

https://doi.org/10.1002/adma.201501372
[5] Zhu C., Han T-Y., Duoss E. B., Golobic A. M., Kuntz J. D., Spadaccini C. M., Worsley M. A.: Highly compressible $3 \mathrm{D}$ periodic graphene aerogel microlattices. Nature Communications, 6, 6962/1-6962/8 (2015). https://doi.org/10.1038/ncomms 7962

[6] Muth J. T., Vogt D. M., Truby R. L., Mengüç Y., Kolesky D. B., Wood R. J., Lewis J. A.: Embedded 3D printing of strain sensors within highly stretchable elastomers. Advanced Materials, 26, 6307-6312 (2014). https://doi.org/10.1002/adma.201400334

[7] Zarek M., Layani M., Cooperstein I., Sachyani E., Cohn D., Magdassi S.: 3D printing of shape memory polymers for flexible electronic devices. Advanced Materials, 28, 4449-4454 (2016). https://doi.org/10.1002/adma.201503132

[8] Kokkinis D., Schaffner M., Studart A. R.: Multimaterial magnetically assisted $3 \mathrm{D}$ printing of composite materials. Nature Communications, 6, 8643/1-8643/10 (2015). https://doi.org/10.1038/ncomms9643

[9] Song J., Lu Y., Luo J., Huang S., Wang L., Xu W., Parkin I. P.: Barrel-shaped oil skimmer designed for collection of oil from spillss. Advanced Materials Interfaces, 2, 1500350/1-1500350/8 (2015). https://doi.org/10.1002/admi.201500350

[10] Shan S., Kang S. H., Raney J. R., Wang P., Fang L., Candido F., Lewis J. A., Bertoldi K.: Multistable architected materials for trapping elastic strain energy. Advanced Materials, 27, 4296-4301 (2015). https://doi.org/10.1002/adma.201501708

[11] Mao Y., Yu K., Isakov M. S., Wu J., Dunn M. L., Qi H. J.: Sequential self-folding structures by $3 \mathrm{D}$ printed digital shape memory polymers. Scientific Reports, 5, 13616/1-13616/12 (2015). https://doi.org/10.1038/srep13616

[12] Yu R., Yang X., Zhang Y., Zhao X., Wu X., Zhao T., Zhao Y., Huang W.: Three-dimensional printing of shape memory composites with epoxy-acrylate hybrid photopolymer. ACS Applied Materials and Interfaces, 9, 1820-1829 (2017). https://doi.org/10.1021/acsami.6b13531

[13] Ge Q., Dunn C. K., Qi H. J., Dunn M. L.: Active origami by $4 \mathrm{D}$ printing. Smart Materials and Structures, 23, 094007/1-094007/15 (2014). https://doi.org/10.1088/0964-1726/23/9/094007

[14] Liu Y., Shaw B., Dickey M. D., Genzer J.: Sequential self-folding of polymer sheets. Science Advances, 3, e1602417/1-e1602417/7 (2017). https://doi.org/10.1126/sciadv.1602417

[15] Ge Q., Qi H. J., Dunn M. L.: Active materials by fourdimension printing. Applied Physics Letters, 103, 131901/1-131901/5 (2013). https://doi.org/10.1063/1.4819837

[16] Ding Z., Yuan C., Peng X., Wang T., Qi H. J., Dunn M. L.: Direct 4D printing via active composite materials. Science Advances, 3, e1602890/1-e1602890/6 (2017). https://doi.org/10.1126/sciadv. 1602890

[17] Gladman A. S., Matsumoto E. A., Nuzzo R. G., Mahadevan L., Lewis J. A.: Biomimetic 4D printing. Nature Materials, 15, 413-418 (2016).

https://doi.org/10.1038/nmat4544 
[18] Huang L., Jiang R., Wu J., Song J., Bai H., Li B., Zhao Q., Xie T.: Ultrafast digital printing toward 4D shape changing materials. Advanced Materials, 29, 1605390/11605390/6 (2017). https://doi.org/10.1002/adma.201605390

[19] Mao Y., Ding Z., Yuan C., Ai S., Isakov M., Wu J., Wang T., Dunn M. L., Qi H. J.: 3D printed reversible shape changing components with stimuli responsive materials. Scientific Reports, 6, 24761/1-24761/13 (2016). https://doi.org/10.1038/srep24761

[20] Ge Q., Sakhaei A. H., Lee H., Dunn C. K., Fang N. X., Dunn M. L.: Multimaterial 4D printing with tailorable shape memory polymers. Scientific Reports, 6, 31110/131110/11 (2016). https://doi.org/10.1038/srep31110

[21] Sun L., Huang W. M., Ding Z., Zhao Y., Wang C. C., Purnawali H., Tang C.: Stimulus-responsive shape memory materials: A review. Materials and Design, 33, 577640 (2012).

https://doi.org/10.1016/j.matdes.2011.04.065

[22] Xie T.: Tunable polymer multi-shape memory effect. Nature, 464, 267-270 (2010).

https://doi.org/10.1038/nature08863

[23] Wischke C., Schossig M., Lendlein A.: Shape-memory effect of micro-/nanoparticles from thermoplastic multiblock copolymers. Small, 10, 83-87 (2014).

https://doi.org/10.1002/smll.201202213

[24] Lee S-H., Jung J-H., Oh I-K.: 3D networked grapheneferromagnetic hybrids for fast shape memory polymers with enhanced mechanical stiffness and thermal conductivity. Small, 10, 3880-3886 (2014). https://doi.org/10.1002/smll.201400624

[25] Yu L., Yu H.: Light-powered tumbler movement of graphene oxide/polymer nanocomposites. ACS Applied Materials and Interfaces, 7, 3834-3839 (2015). https://doi.org/10.1021/am508970k

[26] Ma L., Zhao J., Wang X., Chen M., Liang Y., Wang Z., Yu Z., Hedden R. C.: Effects of carbon black nanoparticles on two-way reversible shape memory in crosslinked polyethylene. Polymer, 56, 490-497 (2015). https://doi.org/10.1016/j.polymer.2014.11.036

[27] Zhao J., Chen M., Wang X., Zhao X., Wang Z., Dang Z-M., Ma L., Hu G-H., Chen F.: Triple shape memory effects of cross-linked polyethylene/polypropylene blends with cocontinuous architecture. ACS Applied Materials and Interfaces, 5, 5550-5556 (2013). https://doi.org/10.1021/am400769j

[28] Liu Y., Zhao J., Zhao L., Li W., Zhang H., Yu X., Zhang $Z$.: High performance shape memory epoxy/carbon nanotube nanocomposites. ACS Applied Materials and Interfaces, 8, 311-320 (2015). https://doi.org/10.1021/acsami.5b08766

[29] Ali W., Gebert B., Hennecke T., Graf K., Ulbricht M., Gutmann J. S.: Design of thermally responsive polymeric hydrogels for brackish water desalination: Effect of architecture on swelling, deswelling, and salt rejection. ACS Applied Materials and Interfaces, 7, 1569615706 (2015).

https://doi.org/10.1021/acsami.5b03878
[30] Guo W., Lu C-H., Orbach R., Wang F., Qi X-J., Cecconello A., Seliktar D., Willner I.: pH-stimulated DNA hydrogels exhibiting shape-memory properties. Advanced Materials, 27, 73-78 (2015). https://doi.org/10.1002/adma.201403702

[31] Wang Z., Zhao J., Chen M., Yang M., Tang L., Dang Z-M., Chen F., Huang M., Dong X.: Dually actuated triple shape memory polymers of cross-linked polycyclooctene-carbon nanotube/polyethylene nanocomposites. ACS Applied Materials and Interfaces, 6, 2005120059 (2014). https://doi.org/10.1021/am5056307

[32] Shah A. A., Schultz B., Zhang W., Glotzer S. C., Solomon M. J.: Actuation of shape-memory colloidal fibres of Janus ellipsoids. Nature Materials, 14, 117-124 (2015). https://doi.org/10.1038/nmat4111

[33] Jochum F. D., Theato P.: Temperature- and light-responsive smart polymer materials. Chemical Society Reviews, 42, 7468-7483 (2013). https://doi.org/10.1039/c2cs35191a

[34] Yang H., Yuan B., Zhang X., Scherman O. A.: Supramolecular chemistry at interfaces: Host-guest interactions for fabricating multifunctional biointerfaces. Accounts of Chemical Research, 47, 2106-2115 (2014). https://doi.org/10.1021/ar500105t

[35] Xu B., Zhang L., Pei Y. T., Luo J. K., Tao S. W., De Hosson J. Th. M., Fu Y. Q.: Electro-responsive polystyrene shape memory polymer nanocomposites. Nanoscience and Nanotechnology Letters, 4, 814-820 (2012). https://doi.org/10.1166/nnl.2012.1393

[36] Luo H., Li Z., Yi G., Zu X., Wang H., Wang Y., Huang H., Hu J., Liang Z., Zhong B.: Electro-responsive silver nanowire-shape memory polymer composites. Materials Letters, 134, 172-175 (2014).

https://doi.org/10.1016/j.matlet.2014.07.071

[37] Wen Z-B., Liu D., Li X-Y., Zhu C-H., Shao R-F., Visvanathan R., Clark N. A., Yang K-K., Wang Y-Z.: Fabrication of liquid crystalline polyurethane networks with a pendant azobenzene group to access thermal/ photoresponsive shape-memory effects. ACS Applied Materials and Interfaces, 9, 24947-24954 (2017). https://doi.org/10.1021/acsami.7b05280

[38] Zhao L., Zhao J., Liu Y., Guo Y., Zhang L., Chen Z., Zhang H., Zhang Z.: Continuously tunable wettability by using surface patterned shape memory polymers with giant deformability. Small, 12, 3327-3333 (2016). https://doi.org/10.1002/smll.201600092

[39] Huang M. T., Ishida H.: Investigation of the boron nitride/polybenzoxazine interphase. Journal of Polymer Science Part B: Polymer Physics, 37, 2360-2372 (1999). https://doi.org/10.1002/(SICI)10990488(19990901)37:17<2360::AID-POLB7>3.0.CO;2-V

[40] Chigwada G., Kandare E., Wang D., Majoni S., Mlambo D., Wilkie C. A., Hossenlopp J. M.: Thermal stability and degradation kinetics of polystyrene/organically-modified montmorillonite nanocomposites. Journal of Nanoscience and Nanotechnology, 8, 1927-1936 (2008). https://doi.org/10.1166/jnn.2008.027 